\title{
PROPAGANDA MONÁRQUICA ESPAÑOLA EN LAS RELACIONES DE SUCESOS: LAS BODAS HISPANO-FRANCESAS DE $1615^{1}$
}

\author{
Álvaro Bueno Blanco \\ (Universidad Carlos III de Madrid) \\ abueno@hum.uc3m.es
}

\section{RESUMEN}

Las dobles bodas celebradas entre las Coronas de Francia y la Monarquía Hispánica fueron un evento tremendamente relevante. Si una unión entre los estados más poderosos del momento siempre lo era, lo que supuso en el contexto de acercamiento entre ambos reinos la hizo aún más destacable. La necesidad política y económica hizo necesaria una campaña de propaganda entre dos potencias enemigas para silenciar las oposiciones internas. Uno de los elementos de esa propaganda más difundidos fueron las relaciones de sucesos, que serán el objeto de estudio de este trabajo, con la finalidad de analizar qué mensajes trató de difundir la monarquía a través de ellas.

PALABRAS CLAVE: relaciones de sucesos; propaganda; bodas reales de 1615

\section{MONARCHY PROPAGANDA IN RELATIONCHIPS OF SUCCESS: 1615 HISPANIC-FRENCH WEDDINGS}

\begin{abstract}
The double royal wedding that took place in 1615 between the Crowns of France and the Hispanic Monarchy was an extremely relevant event. Every alliance between those two states was significant, but the political context made the occasion even more compelling. The Hispanic government took advantage of that importance to develop a great campaign of propaganda. The sources of this paper will be the pamphlets, widely distributed at the Modern Age, with the aim of analyzing the messages that the monarchy tried to send.
\end{abstract}

KEY WORDS: pamphlets; propaganda; 1615 royal weddings.

\footnotetext{
${ }^{1} \mathrm{El}$ presente trabajo forma parte del proyecto de tesis doctoral financiado con un contrato de Formación del Profesorado Universitario (FPU18/01356), del Ministerio de Ciencia, Innovación y Universidades.
} 
El día 9 de noviembre de 1615 se organizó en el río Bidasoa el conocido como «intercambio de princesas», por el que la corte española recibía a Isabel de Borbón, esposa del futuro Felipe IV, y la francesa hacía lo propio con Ana de Austria, casada con Luis XIII. Se ratificaba así el momento de mayor acercamiento entre esas dos coronas, tradicionalmente enfrentadas, tras décadas de conflicto ${ }^{2}$.

Fue, por tanto, un acontecimiento gran relevancia en torno al cual se generó una inmensa cantidad de propaganda, a uno y otro lado de los pirineos ${ }^{3}$. Si habitualmente las bodas eran momentos aprovechados para la producción de publicidad ensalzando a la monarquía, unos dobles matrimonios y más entre miembros de las casas reales de las dos principales potencias de Europa fueron una oportunidad paradigmática para las campañas propagandísticas.

En lo que se refiere al caso español, en el que se centrará este trabajo ${ }^{4}$, la propaganda se desarrolló por distintas vías. Por un lado, hubo una fuerte publicidad visual, con ejemplos como los dos cuadros que conmemoraran el intercambio del Bidasoa $^{5}$, la distribución de numerosos grabados representando los enlaces, o el preponderante papel que desempeñaron las fiestas, habitualmente acompañadas de arquitectura efímera y artificios.

Por otro lado, hubo una gran difusión de propaganda escrita sobre los matrimonios. Este fue el medio de comunicación que logró una mayor difusión en los tiempos modernos, alcanzando sus mayores cotas, precisamente, durante los reinados de Felipe III y Felipe IV ${ }^{6}$. Ejemplos de este tipo de publicidad los encontramos en la

\footnotetext{
${ }^{2}$ Como es bien conocido, con el inicio de las Guerras de Italia en 1494 comenzó un siglo de disputas casi ininterrumpidas entre la Monarquía Hispánica y la corona francesa. A ese enfrentamiento iniciado en el reinado de los Reyes Católicos le siguió la conocida como "pugna Habsburgo-Valois", protagonizada por el enfrentamiento entre Carlos V y Francisco I y la rivalidad de Felipe II con Francia, solo interrumpida apenas una década tras la firma de la Paz de Cateau-Cambresis en 1559.

${ }^{3}$ Si bien el término "propaganda» no comenzó a utilizarse hasta finales del siglo XVIII y principios del XIX, de acuerdo con especialistas en la materia parece aceptado su utilización por los investigadores para referirse a momentos anteriores. Fernando Bouza Álvarez, "La propaganda en la Edad Moderna Española: Medios, agentes y consecuencias de la comunicación política", en Campo y campesinos en la España moderna. Culturas políticas en el mundo hispano, ed. María José Pérez Álvarez y Alfredo Martín García (León: Fundación Española de Historia Moderna, 2012), 284 y 287.

${ }^{4}$ Sobre la propaganda francesa en torno a los matrimonios de 1615 recomendamos la consulta de Héléne Duccini, Faire voir, faire croire. L'opinion publique sous Louis XIII (París: Champ Vallon, 2003); J. Michael Hayden, "Political pamphlets and historians of Early Modern France. The example of 16141615", Canadian Journal of History 21 (1986): 143-165.

${ }^{5}$ Esas representaciones pictóricas, la de Pablo van Mullen conservada en el Alcázar de Sevilla y el anónimo que se encuentra en el monasterio de la Encarnación, han sido trabajadas en María Jesús del Río Barredo, "Imágenes para una ceremonia de frontera. El intercambio de las princesas entre las cortes de Francia y España en 1615”, en La historia imaginada. Construcciones visuales del pasado en la Edad Moderna, dir. Diana Carrió-Invernizzi y Joan Lluís Palos (Madrid: Centro de Estudios Europa Hispánica, 2008), 153-182.

${ }^{6}$ Luis Miguel Enciso Recio, "Los mensajes de la propaganda en la España de Felipe III y Felipe IV. La palabra hablada y la palabra escrita", en Estudios de Historia Moderna en homenaje a la profesora Emilia Salvador Esteban, vol. II, ed. Ricardo Franch Benavent y Rafael Benítez Sánchez-Blanco (Valencia: Publicacions Universitat de Valéncia, 2008), 972.
} 
publicación de diversos libros conmemorando los enlaces ${ }^{7} \mathrm{y}$, fundamentalmente, con una prolífica profusión de relaciones de sucesos. Éstas últimas, publicaciones impresas, de corta extensión, que narraban los acontecimientos más importantes de la época, lograron un gran alcance y capacidad de impacto entre la sociedad del Seiscientos, pues se debe tener en cuenta que, además del público que accediera a ella mediante la lectura, en muchas ocasiones irían unidas a la vía oral mediante la lectura en voz alta, multiplicando así su capacidad de difusión ${ }^{8}$.

Serán precisamente esa vía escrita y, en concreto, las relaciones de sucesos, el objeto principal de este trabajo. En los últimos años se han publicado interesantes trabajos a ese respecto, como el de José María Perceval, quizás el más completo de todos, que analiza principalmente los medios y vías de difusión de la propaganda en torno a las bodas, en sus distintos formatos ${ }^{9}$; o como los de Maldonado Cuns y Arias Saavedra, sobre algunas relaciones concretas ${ }^{10}$. Sin embargo, consideramos necesario poner el foco de atención en los objetivos políticos de las relaciones españolas, algo que, quizás, no era el objetivo principal de ninguna de las investigaciones mencionadas y sí persigue este artículo. Mientras que para el caso francés sí ha sido estudiado ${ }^{11}$.

Cabe recordar que estos impresos no buscaban la descripción objetiva de los hechos, sino transmitir un determinado ideario escogido por el productor de los panfletos. Las relaciones, habitualmente, como en el caso que nos ocupa, emanaban de esferas cercanas al poder, por lo que a principios del siglo XVII eran herramientas para difundir los logros de la monarquía.

Asumiendo esa falta de objetividad, estas publicaciones revisten un grandísimo interés para el investigador, pues suponen un escenario privilegiado para analizar qué imagen trataba de difundir, en un momento determinado, la Corona de sí misma. Así pues, a lo largo de estas páginas trataremos de analizar los mensajes transmitidos por

\footnotetext{
${ }^{7}$ BNE, DGMICRO/54316 : Fray Diego de Noroña, De las bodas de Luys XIII Rey Christianissimo de Francia y Navarra, con doña Anna de Austria Infanta Catholica de España. Dirigido a la Reyna Madre Maria de Medicis, 1616; BNE, R/8664: Pedro Mantuano, Casamientos de España y Francia. Viage del Duque de Lerma llevando la Reyna Christianissima Doña Ana de Austria al passo de Beobia y tragendo a la Princesa de Asturias Nuestra Señora, 1618.

8 Bouza, "La propaganda en la Edad Moderna Española", 281-300.

9 José María Perceval, "Opinión pública y publicidad (siglo XVII). Nacimiento de los espacios de comunicación pública en torno a las bodas reales de 1615 entre Borbones y Habsburgo” (Tesis Doctoral, Universidad Autónoma de Barcelona, 2004).

${ }^{10}$ Inmaculada Arias Saavedra, "Ecos de las alianzas dinásticas entre Francia y España en la imprenta andaluza durante los siglos XVI, XVII y XVIII", Tiempos modernos 36 (2018): 302-330; Ana María Maldonado Cuns, "La relación verdadera de López Maldonado y su paralelismo con otras relaciones de la época para explicar la boda de Ana de Austria y Luis de Borbón”, en Las relaciones de sucesos en los cambios políticos y sociales de la Europa Moderna, coord. Jorge García López y Sonia Boadas Cabarrocas (Barcelona: UAB Servei de Publicacions, 2015), 83-102.

${ }^{11}$ Jean-François Dubost, "La reina de la paz. Conservación, concordia y arte de la diplomacia bajo la regencia de María de Médicis (1610-1614)", en El arte de la prudencia. La Tregua de los Doce Años en la Europa de los Pacificadores, ed. Bernardo José García García, Manuel Herrero Sánchez y Alain Hugon (Madrid: Fundación Carlos de Amberes, 2012); Frédérique Sicard, "La reine dans le théâtre de la Cour d'Espagne: Isabelle de Bourbon, première épouse de Philippe IV' (Tesis Doctoral, Université de Caen, 2012).
} 
la monarquía de Felipe III y cuál era su objetivo propagandístico en un momento tan especial y a la vez tan relevante como las dobles bodas de 1615 .

\section{DE LA PAZ DE VERVINS AL INTERCAMBIO DEL BIDASOA}

La Monarquía Hispánica y Francia, dos de las principales potencias europeas, los «dos grandes luminares de la tierra» ${ }^{12}$, protagonizaron numerosos y casi ininterrumpidos enfrentamientos a lo largo del siglo XVI. Pero esa tendencia belicista finalizó, si bien ni mucho menos de forma definitiva, en 1598 con la firma de la Paz de Vervins ${ }^{13}$, la cual dio inicio a un periodo de paz que se prolongó hasta 1635 , con la entrada formal de Francia en la Guerra de los Treinta Años.

Pero esa paz, en distintos momentos desde la firma del tratado, se mostró enormemente endeble. No hay que olvidar que, pese a lo acordado en Vervins, seguían siendo los principales rivales y los más firmes candidatos a dominar Europa. El acuerdo se había alcanzado por el agotamiento de ambos estados más que por una verdadera voluntad de entendimiento, especialmente en lo que respecta a Francia. Enrique IV se vio obligado a poner fin a las hostilidades exteriores para poder centrar sus esfuerzos en reconstruir un reino que había quedado muy dañado por las Guerras de Religión, pero, pese a ello, dio distintas muestras de una actitud marcadamente antiespañola a lo largo de todo su reinado ${ }^{14}$.

Una política que se planeó especialmente agresiva a finales de la década, cuando el francés inició, en invierno de 1609, preparativos militares para reemprender acciones bélicas contra territorios de los Habsburgo, con el Rin, Italia y los Pirineos como primeros objetivos ${ }^{15}$. Unas campañas que finalmente no pudieron llevarse a cabo por el asesinato del monarca en 1610.

Dado que el heredero al trono, Luis XIII, tenía tan solo nueve años, su madre y esposa del rey difunto, María de Médicis, asumió el gobierno de regencia. La actitud de la reina madre fue completamente opuesta a la de Enrique IV, pues estaba convencida de que Francia debía conservar la paz y la concordia por todos los medios posibles $^{16}$, y de que la piedra angular de ese proyecto debía ser el acercamiento a la Monarquía Hispánica. Se debe tener en cuenta que María de Médicis encabezaba el

${ }^{12} \mathrm{BNE}, \mathrm{R} / 5149$ : Carlos García, La oposición y conjunción de los dos grandes luminares de la Tierra, 1617.

${ }^{13}$ Sobre la Paz de Vervins cabría destacar algunos trabajos como Jean-François Labourdette, JeanPierre Poussou y Marie-Catherine Vignal, eds., Le Traité e Vervins (Paris: Presses de l'Université de ParisSorbonne, 2000); Claudine Vidal y Frédérique Pilleboue, eds., La paix de Vervins: 1598 (Laon: Fédération des sociétés d'histoire et d'archéologie de l'Aisne,1998).

14 Antonio Eiras Roel, "La política francesa de Felipe III: las tensiones con Enrique IV", Hispania 118 (1971): 245-336; Alain Hugon "La monarquía francesa en la borrasca de las paces. De Vervins a los matrimonios con los Habsburgo (1598-1615)", en Tiempo de Paces. La Pax Hispanica y la Tregua de los Doce Años, dir. Bernardo José García García (Madrid: Fundación Carlos de Amberes, 2009), 127-142.

${ }^{15} \mathrm{~J}$. Michael Hayden, "Continuity in the France of Henri IV and Louis XIII: French foreign policy (1589-1615)", Journal of Modern History XLV (1973): p. 147.

${ }^{16}$ Dubost, "La reina de la paz". En ese capítulo el autor analiza con profundidad la política de paz desarrollada por el gobierno de María de Médicis. 
partido católico conocido como dévots ${ }^{17}$, defensores de la implantación del catolicismo y de los valores de la Contrarreforma en Francia y quienes, de acuerdo con Ruiz Ibáñez, veían en España el modelo de la reforma religiosa ${ }^{18}$. Por lo tanto, la política prohabsbúrgica pretendía reforzar el catolicismo francés al tiempo que buscaba fortalecer al propio gobierno de regencia al aliarse con una de las mayores potencias de la Europa de principios del siglo XVII ${ }^{19}$.

Por su parte, la Monarquía Hispánica estaba desarrollando la política conocida como Pax Hispanica, precisamente iniciada con la firma del Tratado de Vervins, que caracterizó a buena parte del reinado de Felipe III y al valimiento del duque de Lerma ${ }^{20}$. Eso alejaba cualquier pretensión de retomar las hostilidades con Francia, más bien todo lo contrario, tras la muerte de Enrique IV la amistad con Francia se convirtió en un eje fundamental de la política pacifista.

Para hacer efectivo ese acercamiento entre ambas coronas se optó por retomar la cuestión de un acuerdo matrimonial, planteada tras la firma del Tratado de Vervins pero que no se había podido concretar en un entendimiento. Pese a la actitud ya mencionada del gobierno de Enrique IV, se realizaron varios intentos de concertar un enlace para ratificar la paz de 1598, si bien con escaso éxito. El primero de ellos fue en 1601, al concluir la Cuestión de Saluzzo, mencionada previamente, pero no se pudo llegar a un acuerdo por la cercanía francesa a los rebeldes holandeses, mismo motivo que truncó las negociaciones en 1602 y en 1603. En 1608 se reiniciaron con fuerza las conversaciones para conseguir alcanzar un acuerdo para el enlace entre Ana de Austria y el Delfín de Francia y el infante don Carlos y Cristina María, la segunda hija de Enrique IV, pero, de nuevo, no pudo materializarse el acuerdo ${ }^{21}$.

La política favorable del gobierno de regencia francés hizo que, al retomar las negociaciones, resultara sencillo llegar a un entendimiento. Las conversaciones se reiniciaron poco después del asesinato de Enrique IV y en 1611 se firmó el Tratado de Fontainebleau, un principio de acuerdo en el que se establecían las uniones del príncipe Felipe con la infanta Isabel de Borbón y de Luis XIII con la infanta Ana de Austria. No obstante, aún hubo que esperar un año más para firmar las definitivas capitulaciones matrimoniales, pues la negociación se ralentizó al tratar el aspecto de la renuncia de la infanta española a la herencia de la Corona de la Monarquía Hispánica.

\footnotetext{
${ }^{17}$ Para un análisis en profundidad de esta facción recomendamos la consulta de B. Pierre, "El partido devoto y la paz en Francia en la década de 1610", en El arte de la prudencia. La Tregua de los Doce Años en la Europa de los Pacificadores, ed. Bernardo José García García, Manuel Herrero Sánchez y Alain Hugon (Madrid: Fundación Carlos de Amberes, 2012), 345-364.

${ }^{18}$ José Javier Ruiz Ibáñez, “Cette disgracê de guerre. La opción española en la política francesa de 1598 a 1641”, en SANZ CAMAÑES, P. (coord.), La Monarquia Hispánica en tiempos de El Quijote, coord. Porfirio Sanz Camañes (Madrid: Sílex, 2005), 539.

${ }^{19}$ Dubost, "La reina de la paz".

${ }^{20}$ Esa política de paz ha sido profundamente estudiada en obras como Paul Allen, Felipe III y la Pax Hispanica (1598-1621) (Madrid: Alianza Editorial, 2001); Bernardo José García García, La Pax Hispanica. Política exterior del duque de Lerma, (Lovaina: Leuven University Press, 1996).

${ }^{21}$ Hayden, "Continuity in the France of Henri IV and Louis XIII", 147; Alain Hugon, Au service du Roi Catholique: Honorables ambassadeurs et divins espions face à la France (Madrid : Casa de Velázquez, 2004), 64-66.
} 
Finalmente, en 1612 pudo certificarse el acuerdo con la firma de las capitulaciones matrimoniales y el anuncio público. Tres años después se harían efectivos los matrimonios y se produciría el mencionado encuentro del Bidasoa.

\section{ANUNCIO DEL ACUERDO Y FIRMA DE LAS CAPITULACIONES}

Una vez alcanzado el esperado acuerdo, se procedió al anuncio oficial en ambas cortes. En Madrid se hizo el 2 de febrero de 1612, coincidiendo con la procesión de la Candelaria, y el 25 de marzo en París ${ }^{22}$. Como complemento a esas comunicaciones se organizaron fiestas de celebración por los enlaces, las cuales son los primeros hechos relativos a las bodas que se reflejan en las relaciones de sucesos.

\subsection{Fiestas por el anuncio de los casamientos}

Las fiestas que acompañaban en la Edad Moderna el anuncio de decisiones tomadas por los monarcas fueron un elemento de propaganda de primer orden, pues contribuían a una mejor aceptación de la resolución y adhesión social. Una idea ya planteada en el clásico trabajo de José Antonio Maravall ${ }^{23}$. Además, de acuerdo con Perceval, las celebraciones relatadas en escritos como las relaciones de sucesos deslumbraban aún más que las reales, por lo que la inclusión de éstas en los panfletos era fundamental en las campañas de propaganda reales ${ }^{24}$. Así, no parece aleatorio que las primeras noticias que se difundieron sobre las bodas fueran, precisamente, descripciones de las fiestas celebradas tras conocerse los acuerdos. Se pretendía así buscar la mayor cohesión social posible a la noticia desde el primer momento en que se hacía pública, tratando de minimizar la oposición que pudiera surgir a la alianza hispano-francesa.

En Madrid, en febrero de 1612, continuaba el luto por la muerte de la reina Margarita de Austria, por lo que el protocolo impedía que se celebraran fiestas. En cambio, sí se han conservado panfletos describiendo festejos que tuvieron lugar en los territorios italianos de la Monarquía Hispánica ${ }^{25}$.

En Nápoles los actos más importantes se desarrollaron en la plaza frente al palacio virreinal. El espacio se decoró para la ocasión con un amplio cadalso destinado a acoger un torneo; y una montaña artificial en uno de los laterales de la plaza. Los festejos comenzaron a la una del mediodía del día 15 de mayo con la entrada, desde la montaña artificial antes mencionada, de una vistosa comitiva formada por

\footnotetext{
22 María José del Río Barredo, "Infancia y educación de Ana de Austria en la Corte española (16011615), en Ana de Austria. Infanta de España y reina de Francia, dir. Chantal Grell (Madrid: Centro de Estudios Europa Hispánica, 2009), 26-27.

${ }^{23}$ José Antonio Maravall, La Cultura del Barroco. Análisis de una estructura histórica (Barcelona: Ariel, 1975).

24 Perceval, Opinión pública y publicidad, 136 y 212.

${ }^{25}$ Universidad de Barcelona, Biblioteca General, Área de Reserva, B-59/3/42-44: Relacion verdadera sacada de un original muy fidedigno, de las fiestas que se han hecho en Napoles a 15 de Mayo deste presente año para celebrar el casamiento de la Magestad del Rey de Francia, con la Infanta nuestra Señora, Barcelona, 1612.
} 
representaciones de animales fantásticos como grifos, dragones, elefantes o avestruces; tras ellos hicieron su aparición el conde de Villamediana, quien sufragaba los gastos del torneo, y el virrey el conde de Lemos, seguidos de otros miembros de la aristocracia, tanto española como de otras partes de Italia. Este panfleto detalla los gastos de los festejos, que sumaron ciento cincuenta mil ducados, pero que estuvieron «bien empleados pues en esa fiesta se reconoce la fidelidad y amor que los vasallos tienen a sus reyes, y en casamientos reales que aseguren la paz y la exaltación de la fe y la total extirpación de las herejías de Francia» ${ }^{26}$. Una afirmación que explicita la función de la fiesta barroca de búsqueda de cohesión social, como afirmábamos anteriormente.

$\mathrm{Al}$ igual que en Nápoles, fiestas similares fueron celebradas en $\mathrm{Mesina}^{27}$, y, con gran probabilidad, en más ciudades italianas de la Monarquía, aunque no hemos podido acceder a relaciones que las describieran.

Por su parte, en la capital francesa tuvo lugar una fastuosa celebración en la Place Royale los días 5, 6 y 7 de abril de ese año 1612, de la que también se hicieron eco las relaciones publicadas en España. Como se reflejó para los festejos de Nápoles, la plaza parisina fue engalanada para la ocasión con la construcción de un gran castillo artificial en el centro de la misma y con la disposición en los laterales de tablados y galerías para la familia real y la aristocracia. Según los panfletos españoles, las fiestas fueron lideradas por el duque de Guisa y los más destacados nobles, así como los Príncipes de la Sangre. Que se incluyera la buena disposición de estos últimos a participar en las celebraciones reviste una gran importancia pues eran los principales opositores al gobierno de regencia, como ampliaremos más adelante ${ }^{28}$.

Durante los tres días que duraron los festejos se produjeron entradas y desfiles en los que los más destacados miembros de la aristocracia, ataviados de ricos ropajes y acompañados de opulentos carruajes y representaciones alegóricas de la prosperidad que llevarían a ambos reinos los enlaces entraban a la plaza para regocijo de los presentes; torneos de lanzas; fuegos artificiales y luminarias; y salvas de artillería diarias. Todo ello en presencia del embajador español, que durante esas jornadas de celebración estuvo alojado en el palacio real y agasajado con suntuosos banquetes ${ }^{29}$.

A lo largo de las descripciones sobre las fiestas de París se suceden expresiones como «los mayores reyes del universo», haciendo alusión tanto a la monarquía francesa

\footnotetext{
${ }^{26}$ Universidad de Barcelona, Biblioteca General, Área de Reserva, B-59/3/42-44: Relacion verdadera sacada de un original muy fidedigno, de las fiestas que se han hecho en Napoles a 15 de Mayo deste presente año para celebrar el casamiento de la Magestad del Rey de Francia, con la Infanta nuestra Señora, Barcelona, 1612.

${ }^{27}$ Roger Chartier, ed., Les Usages de l'imprimé (Paris: Fayard, 1986), 60.

${ }_{28}^{8} \mathrm{BNE}, \mathrm{VE} / 1407 / 22$ : Relacion de las fiestas que los Principes y Nobleza de Francia por mandado de los Reyes Christianissimos han hecho a la alegria de los casamientos de España, Lisboa, 1612; Las fiestas que se hicieron en París por los felices casamientos de los Reyes de Francia con los de España, sabido por relación muy verdadera, en este presente año de mily seiscientos y doce, Granada, 7 de junio de 1612. Referencia opbtenida de Arias Saavedra, "Ecos de las alianzas dinásticas", 302-330.

${ }^{29} \mathrm{BNE}, \mathrm{VE} / 1407 / 22$ : Relacion de las fiestas que los Principes y Nobleza de Francia por mandado de los Reyes Christianissimos han hecho a la alegria de los casamientos de España, Lisboa, 1612; Las fiestas que se hicieron en Paris por los felices casamientos de los Reyes de Francia con los de España, sabido por relación muy verdadera, en este presente año de mil y seiscientos y doce, Granada, 7 de junio de 1612. Referencia opbtenida de Arias Saavedra, "Ecos de las alianzas dinásticas", 302-330.
} 
como a la española, o «la mayor belleza del universo, que era la princesa y reina suya», refiriéndose a Ana de Austria; así como constantes menciones a la prosperidad que llevaría al reino el enlace matrimonial. Mostraban, de esa forma, que la sociedad gala había acogido con gran felicidad la noticia de que la infanta española se convirtiera en su reina.

Esto contrasta con la relación que narra las celebraciones en Nápoles, en la cual no hay ninguna mención a Isabel de Borbón ni a que la unión con Francia fuera a resultar especialmente provechosa para España, al contrario, se especifica que la asociación con el país galo era porque permitiría que la Monarquía Hispánica, adalid de la cristiandad, ayudara a extirpar la herejía del reino vecino.

Se transmitía en las relaciones de sucesos españolas una inequívoca idea de rivalidad entre ambos estados, pese a la alianza Francia seguía siendo el principal competidor de la monarquía de Felipe III, por lo que era muy importante sugerir que la Monarquía Hispánica era superior a Francia, pudiendo llevar prosperidad y unión religiosa un territorio que atravesaba momentos de inestabilidad en esos aspectos.

También se desprende otra idea importante de las descripciones de las fiestas, la de la cohesión de la aristocracia de ambos reinos en torno a sus respectivos gobernantes. Esto es algo especialmente notable en el caso francés, pues la adhesión de la nobleza, al menos de parte de ella, al gobierno de regencia no fue tan completa como se muestra en el panfleto. El anuncio del acuerdo con la Monarquía Hispánica provocó la oposición de un importante grupo de la aristocracia francesa, entre los que destacaron los Príncipes de Sangre encabezados por el príncipe de Condé, así como de los principales líderes hugonotes. Este grupo se mostró contrario al gobierno de María de Médicis durante toda la regencia, pero se opuso especialmente a ningún acercamiento a España, contando con los motivos religiosos como su principal argumento. De esa forma, tras el pacto hispano-francés decidieron abandonar la corte dando inicio a una rebelión que duró, interrumpida por algunos periodos de negociación, hasta $1614^{30}$.

Sin embargo, este rechazo a un acuerdo franco español no convenía que se reflejara en la propaganda hispánica, pues se trataba de difundir la imagen de que España haría mejorar a Francia, no crear una oposición tan fuerte que llevaría al reino al límite de una nueva guerra civil. Por esa razón en las relaciones, tanto las ya mencionadas como las que trataremos en las siguientes páginas, se hace especial hincapié en especificar que los Príncipes y las Princesas de Sangre están junto a la regente y participan en todos los actos relativos a los matrimonios, pese a que, en muchas ocasiones, eso no se correspondiera con la realidad.

También se debe tener en cuenta que en la Monarquía Hispánica existió cierta oposición a la política pacifista del duque de Lerma, si bien no alcanzó, ni mucho

\footnotetext{
${ }^{30}$ Duccini, Faire voir, faire croir. 117-121.
} 
menos, las cotas de desobediencia francesas. Eran los denominados reputacionistas, defensores de que la pax hispanica suponía una pérdida de reputación ${ }^{31}$.

\subsection{Embajadas extraordinarias para la firma de las capitulaciones matrimoniales}

Sobreponiéndose a ese clima de inestabilidad interna del reino galo, en verano de 1612 se llevó a cabo la firma de las capitulaciones matrimoniales mediante el envío como embajadores extraordinarios para tal fin del duque de Pastrana por parte de Felipe III y del duque de Humena por la de la reina regente de Francia.

Sobre la misión diplomática del embajador español en París tan solo se ha conservado una relación. Según este documento, el duque entró en la capital francesa el trece de agosto, siendo recibido y acompañado hasta su residencia por una comitiva que encabezaba el duque de Nevers. Allí acogió, la misma noche de su llegada, la visita de enviados del rey y la reina madre, si bien no fue a palacio hasta el jueves dieciséis.

Ese día Pastrana llegó al encuentro guiado por el duque de Guisa, quien le había recogido en su residencia para acompañarle hasta el Palacio del Louvre, donde llegaron al anochecer. Habían acudido como espectadores «numerosos caballeros españoles y franceses», y esperaban al embajador, en una tarima construida para la ocasión en una de las galerías del palacio, el rey junto a su madre, las princesas de Sangre, encabezadas por la de Condé, y las mujeres de los Pares de Francia.

Tras un tiempo de conversación con los presentes y la entrega de las cartas que el diplomático llevaba de parte de Felipe III, que despertaron «grandes demostraciones de contento» en la regente y su hijo, el duque se dirigió a los aposentos de la infanta Isabel, la cual recibió también con gran regocijo los recados que le dio Pastrana. Tras presentar sus respetos a la futura princesa de Asturias todos los caballeros españoles que acompañaban al diplomático, pasó el embajador a hacer lo propio con el hermano menor del rey antes de regresar a su residencia, de nuevo acompañado por el duque de Guisa.

El día fijado para la firma de las capitulaciones era el sábado veinticuatro de agosto, una fecha simbólica por ser la festividad de San Luis, una de las principales en Francia. En esa ocasión, según la relación, fue el príncipe de Conti, tío del príncipe de Condé, quien fue a buscar al duque de Pastrana para acompañarlo hasta palacio. La sala escogida para el encuentro ya no era una galería, si no el propio cuarto del rey. Estaban presentes el propio Luis XIII, María de Médicis, las infantas Isabel y Cristina, la reina Margarita, primera mujer del difunto Enrique IV, todos los Príncipes y Princesas de Sangre, los Pares de Francia y sus esposas, y otros muchos representantes de la aristocracia gala. También había un nutrido grupo de representantes de otras cortes, como el nuncio papal u otros embajadores.

${ }^{31}$ Esa oposición a la política desarrollada por el valido ha sido muy bien estudiada por Antonio Feros en El duque de Lerma. Realeza y privanza en la España de Felipe III (Madrid: Marcial Pons, 2002), 439480. 
Tras las pertinentes cortesías, se leyeron en voz alta las capitulaciones y se procedió a su firma. Acabadas las felicitaciones posteriores, Pastrana regresó a su residencia dejando en palacio «una alegría común que en general se vio».

El último evento que se destaca en la relación fue un banquete celebrado el veintiséis de agosto al que fue invitado el duque de Pastrana y el embajador ordinario en Francia, don Íñigo de Cárdenas. En él estuvieron presentes los reyes y la infanta Isabel, así como las Princesas de Sangre y duquesas, aunque esta vez no lo hicieron los Príncipes de Sangre. El banquete estuvo acompañado de bailes, entre los que se destaca en el panfleto el del embajador con la infanta Isabel. Acabada la celebración, el duque regresó a su residencia y se puso fin a su misión extraordinaria ${ }^{32}$.

A diferencia de lo reflejado en las relaciones que se hacían eco de las fiestas celebradas en París unos meses antes, la descripción de la embajada de Pastrana no refleja tanto dispendio y esplendor como las anteriores. Posiblemente esto se trate porque, una vez difundida la idea de que Francia necesitaba de la unión con la Monarquía Hispánica para su propia prosperidad y era motivo de gran alegría acoger a una infanta española, el siguiente objetivo de la propaganda de Felipe III era transmitir la boyante situación por la que atravesaban sus reinos. Para eso, se hará hincapié, como veremos a continuación, en la descripción de las riquezas y los gastos efectuados en la corte de Madrid en contraposición a las observables en París. De esa forma, se ensalza la situación de la Monarquía Hispánica describiéndola a ésta y también mostrándola muy superior a Francia, que no dejaba de ser, reiteramos, su principal rival político.

De la misión del embajador francés en Madrid nos han llegado un mayor número de relaciones. En ellas se describe con gran profusión de detalles la misión del enviado extraordinario, el duque de Humena, de las Casas de Guisa y Lorena, Príncipe de la Sangre y camarero mayor del rey. El francés, en su llegada a la capital, se detuvo en el cercano pueblo de Barajas. Allí fue recibido por el duque de Alba y un nutrido grupo de nobles españoles para poder efectuar una entrada solemne en la corte junto con su séquito de «más de setecientas personas, y entre ellas setenta señores de título y de la mayor nobleza de Francia» ${ }^{33}$.

Una vez en Madrid, el embajador se hospedó en las casas del marqués Spínola, en la Carrera de San Jerónimo. Unas dependencias que habían sido ricamente decoradas para la ocasión, según se describe en los panfletos. Allí, Humena recibió la

\footnotetext{
32 Biblioteca Universitaria de Sevilla, A109/085 (081). Relacion de la audiencia que se le dio al Principe de Merito, Duque de Pastrana embaxador extraordinario, en Paris por los Cristianissimos Reyes de Francia, y embaxada que les dio, y el efecto que vno cerca de las Capitulaciones de los casamientos del Principe nuestro Señor, y de la serenissima Infanta Madama Isabela, y de lo que mas passo, Madrid, 1612.

${ }^{33}$ Entrada suntuosa en la Corte de Madrid el Duque de Umena, Embaxador, y Grande de Francia, por los Christianissimos Reyes della, para el efecto de los dichosos casamientos, cuyas capitulaciones se ban de celebrar, y concluyr assi en España, como en Francia, para nuestra Señora Santa Maria de Agosto, y basta entonces duran los lutos por la Catolica Magestad de la Reyna nuestra señora. Y del gran recibimiento que se le hizo por los titulos y señores de la Corte, y de lo que passo en su yda a Palacio a dar la Embaxada al Rey nuestro señor, y a la Reyna de Francia señora suya, y nuestra, y con la alegria que fue recibido, Granada, 1612. Referencia obtenida de José Simón Díaz, ed., Relaciones de actos públicos celebrados en Madrid, (1541-1650), (Madrid: Instituto de Estudios Madrileños, 1982), 80-82.
} 
visita, la noche de su llegada, del marqués de la Laguna como enviado del rey, del nuncio papal y embajadores extranjeros, así como de los Grandes de España y títulos destacados, entre los que se resalta en las relaciones al duque de Lerma, acompañado de su familia. Desde este momento en adelante, el valido, su familia y los cortesanos más cercanos a su persona, estarán omnipresentes en las relaciones de sucesos, mostrando de forma clara su situación de poder. De esa forma se evidencia que estos panfletos no eran útiles únicamente para transmitir mensajes desde el poder, sino también para evidenciar quién ostentaba dicho poder.

La primera visita a palacio, el día siguiente a su llegada, fue para dar el pésame a Felipe III por el fallecimiento de Margarita de Austria, en esa ocasión con el duque de Uceda, hijo del duque de Lerma, como acompañante del embajador. En el Real Alcázar fue recibido con honores por los capitanes de las Guardas Españolas, Tudesca y arqueros, así como por los mayordomos del rey, antes de ser conducido a la presencia del monarca. En la audiencia con el soberano estuvieron también presentes los Grandes de España. Igual que había hecho el duque de Pastrana en París, Humena entregó las cartas y los recados de los reyes de Francia y, una vez finalizada la entrevista, pasó junto con sus acompañantes franceses al cuarto de la infanta Isabel a presentar sus respetos ${ }^{34}$.

El siguiente encuentro con los reyes ya fue para la firma de las capitulaciones matrimoniales, también el día de San Luis, pues se había acordado que en ambas cortes se rubricara el acuerdo el mismo día. Con ese motivo se había mandado levantar el luto de la corte madrileña, para poder celebrar la firma como merecía el acontecimiento. Así, la comitiva francesa pudo lucir ricas galas y joyas, prolíficamente descritas en las relaciones. No obstante, el lujo mostrado por los caballeros españoles no se quedó atrás, siendo difícil juzgar «cuál de las dos era mejor porque todas eran riquísimas» ${ }^{35}$. El duque de Humena fue recogido en su residencia por el duque de Lerma quien se encargó de apadrinarle en esa ocasión, acompañado de un buen número de Grandes y títulos.

El cortejo salió de la residencia del embajador de Francia a las cuatro de la tarde, dirigiéndose a palacio por la calle Mayor. A lo largo de esa vía se habían ocupado todas las galerías y ventanas por la muchedumbre que querían ver pasar a los caballeros españoles y franceses. Eran ya las seis de la tarde cuando llegaron al Palacio Real, donde se había engalanado el patio con tapices y la «sala grande» se había preparado para la recepción. Allí se firmaron las capitulaciones, en un acto que duró apenas dos horas. No hubo fiestas posteriores a la rúbrica, pero sí, el domingo de esa semana, veintiséis de agosto, Felipe III quiso honrar públicamente al duque de Humena. Para ello lo recibió nuevamente en palacio, tras el correspondiente desfile por la calle Mayor, desde donde salió el monarca con el embajador a su lado recorriendo las calles madrileñas hasta la residencia del duque de Lerma, donde estuvieron un breve tiempo y regresaron

\footnotetext{
34 Ibidem.

35 Universidad de Barcelona, Biblioteca General, Área de Reserva, B-59/3/42-40: Relacion verdadera de las capitulaciones se hizieron entre el Principe nuestro Señor y la Infanta de Francia, y de la Infanta de España con el Rey de Francia, Barcelona, 1612.
} 
al Palacio Real. De esa forma se dio por concluido el acto y se esperaba la pronta partida del diplomático hacia París ${ }^{36}$.

De la descripción que hacen las relaciones de sucesos de las firmas en una y otra corte cabe destacar, de nuevo, la mención expresa que realizan a la presencia constante de los Príncipes de Sangre en los actos en París. Igualmente, es en la capital francesa donde se relatan, de forma explícita, muestras de alegría por la unión con la Monarquía Hispánica y porque Ana de Austria fuera a ser la reina de Francia, incidiendo así en la idea de que la unión española sería especialmente beneficiosa para los franceses. En cambio, sobre los actos en Madrid las descripciones ponen el foco de atención en las riquezas, presentadas como superiores, y en el trato y agasajo dispensados al duque de Humena, que profundizan en la noción de opulencia de la Monarquía Hispánica. Tratan así de sugerir que España era muy superior al reino vecino en ese momento, tanto políticamente como en esplendor.

Pese a la firma de las capitulaciones matrimoniales en ese verano de 1612, hubo que esperar aún tres años más para la celebración de los enlaces. No se ha llegado aún un consenso para explicar ese retraso, aunque una de las teorías más aceptadas es que fue la oposición a María de Médicis que hemos mencionado anteriormente lo que provocó la demora ${ }^{37}$. Inicialmente, se habría fijado 1614 como fecha para la celebración de las nupcias, pero una nueva insurrección liderada por Condé, ese mismo año, obligó a posponerla. La regente consideraba demasiado inestable emprender una jornada hasta la frontera con ese clima de inestabilidad política, por lo que decidió esperar hasta sofocar la revuelta ${ }^{38}$.

Sin embargo, continuando con la tendencia de transmitir una idea de absoluta ausencia de problemas y de oposición a los gobiernos, en las relaciones españolas no se hizo mención alguna a ese retraso, al contrario, se afirmaba que las bodas tuvieron lugar en 1615 «por haberse pasado los tres años, que fue el tiempo asignado para las entregas $\rangle^{39}$.

\section{LAS DOBLES BODAS DE 1615}

Los gobiernos de Francia y la Monarquía Hispánica negociaron las condiciones de los matrimonios de 1615 pretendiendo que dominara la más absoluta igualdad entre

36 Universidad de Barcelona, Biblioteca General, Área de Reserva, B-59/3/42-40: Relacion verdadera de las capitulaciones se hizieron entre el Principe nuestro Señor y la Infanta de Francia, y de la Infanta de España con el Rey de Francia, Barcelona, 1612; Biblioteca Universitaria de Sevilla, A109/085 (081): Relacion verdadera en la qual se declara la embaxada que dio el Duque de Umena, y capitulaciones entre España, y Francia; Relación verissima del efecto, y fin de los conciertos del felicissimo casamiento de la serenissima Infanta de Castilla doña Ana Mauricia de Austria, con el muy catolico Ludovico Rey de Francia, decimo tercio deste nombre, cuyas condiciones se firmaron en Palacio, a veynte y dos de Agosto, por el duque de Umena, Málaga, 1612. Referencia obtenida de Simón Díaz, Relaciones de actos públicos, 85-87.

${ }^{37}$ Duccini, Faire voir, faire croir, 177; García García, La Pax Hispanica, 91-93; Perceval, Opinión pública y publicidad, 61; Río Barredo "Infancia y educación de Ana de Austria", 28.

38 Pierre Chevallier, Louis XIII (París: Fayard, 1979), 97.

39 Relacion de la iornada, y casamientos, y entregas de España, y Francia, s. 1., s. a. Referencia obtenida de Simón Díaz, Relaciones de actos públicos, 94-98. 
ambas cortes. Ya se había buscado esa equidad al acordar que las contrayentes fueran las infantas de mayor edad y que sus dotes fueran iguales, una línea que continuó en los actos de $1615^{40}$. Así, las bodas se celebrarían por poderes en los respectivos reinos antes del intercambio de las princesas, unas ceremonias que debían tener lugar el mismo día y en ciudades a la misma distancia de la frontera, siendo las escogidas Burgos y Burdeos. Finalmente, el encuentro de ambas cortes se produciría en la frontera entre los dos reinos, siendo el río Bidasoa el lugar escogido.

\subsection{Las ceremonias de Burgos y Burdeos}

Mientras que las relaciones de sucesos que describen lo acaecido en España, como más tarde analizaremos, inician su narración desde la salida de la infanta de Madrid, las referidas a la corte francesa lo hacen cuando se esta se encuentra ya en Burdeos. La comitiva francesa llegó a la ciudad establecida para la celebración del matrimonio el 7 de octubre, casi un mes después de que la española arribara a Burgos. Una vez ambos séquitos se encontraron en las villas acordadas, el intercambio de correspondencia se intensificó para fijar la fecha de las bodas por poderes, estableciéndose finalmente el 18 de octubre ${ }^{41}$.

El día 17 Íñigo de Cárdenas, embajador ordinario en Francia, tuvo audiencia con los reyes, en la que, de nuevo, estaban presentes los Príncipes y Princesas de la Sangre, Pares, duques y miembros destacados de la corte. En este encuentro el diplomático español comunicó a Luis XIII y a todos los presentes que Felipe III le concedía poderes al duque de Guisa para contraer matrimonio con la infanta Isabel en nombre del príncipe. Una vez hecha la notificación al soberano, el propio Cárdenas se dirigió a la residencia de Guisa para entregarle a él el poder, el cual recibió el francés «con gran veneración y respeto».

$\mathrm{Al}$ día siguiente el embajador español fue recogido por el Príncipe de Ienuile para ir a buscar al duque de Guisa y dirigirse a palacio. Allí salieron a recibirles el rey, María de Médicis y la infanta, según las relaciones llevada por su hermano del brazo y por su madre de la mano. En las descripciones destacan los ropajes que llevaba Guisa, el rey y la infanta, mientras que la reina regente iba de negro por su condición de viuda «pero con algunas joyas, aunque pocas». Continuaba de esa forma la línea iniciada ya con las relaciones que describían la embajada del duque de Pastrana de mostrar mucho mayor esplendor en joyas y riquezas en la corte de Felipe III que en la de Luis XIII, como mostraremos más adelante.

Estuvieron conversando, según la relación, durante una hora, en la galería de palacio donde los monarcas habían recibido a Cárdenas. Desde allí se encaminaron hacia la iglesia formando una comitiva encabezada por los extranjeros que habían seguido a la corte; después los oficiales de la Corona; tras ellos doce Reyes de Armas; a continuación, duques y Pares, precediendo al embajador español, al duque de Guisa, los reyes y la princesa; por último, cerrando la comitiva, todos los cargos de la Casa del

\footnotetext{
${ }^{40}$ Río Barredo, “Imágenes para una ceremonia de frontera”, 159-161.

${ }^{41}$ Chevallier, Louis XIII, 97-99.
} 
Rey. A los lados del cortejo fueron doce trompetas reales tocando durante todo el recorrido. Todos ellos escoltados por la guarda personal del rey.

De esa forma llegaron a la iglesia, engalanada para la ocasión de una forma riquísima, descrita minuciosamente en las relaciones, con tapices, paños labrados de oro y seda y terciopelos decorados con flores de lis. Frente al altar se habían ubicado tres sillas que ocuparon la infanta Isabel, sentada en la del medio, el rey a su derecha y su madre a la izquierda. «A mano derecha, estaban en un escalón en alto» dos sillas que ocuparon Guisa y Cárdenas.

El encargado de oficiar la ceremonia fue el cardenal de Sourdis, quien unió en matrimonio a Isabel de Borbón y al príncipe Felipe de Habsburgo, representado por el duque de Guisa. Acabada la ceremonia, los reyes regresaron a palacio y se iniciaron las celebraciones por la ciudad, descritas mucho más brevemente que aquellas celebradas en 1612. Se reflejan las salvas de artillería que se dispararon por toda la villa, «toda la ciudad eran fuegos y alegrías que parecía que la ciudad se hundía» ${ }^{42}$, aunque no se detalla más en qué consistieron esas alegrías ${ }^{43}$.

Ya como esposa del príncipe Felipe, Isabel de Borbón salió el día 21 de octubre de Burdeos rumbo al punto fijado para el intercambio, el río Bidasoa, sin la compañía de María de Médicis, que prefirió quedarse en la ciudad francesa ${ }^{44}$.

Las relaciones de sucesos que se centran en la boda de Ana de Austria son mucho más extensas en su contenido que las descritas para el enlace celebrado en Francia. Como ya hemos mencionado previamente, inician la descripción de los hechos cuando la infanta aún está en Madrid. Se refleja que, antes de su salida de la corte, la futura reina de Francia se despidió de varios monasterios de monjas, siendo el último el de las Descalzas Reales, donde se encontraba su tía. Allí, además, recibió la visita de algunas damas destacadas de la ciudad que le presentaron sus respetos. Concluidas las despedidas, la comitiva formada por el rey y la reina, el príncipe, los infantes, los cargos de palacio y grandes títulos partió hacia Burgos. Una vez llegaran allí, Felipe III había encomendado al duque de Lerma que se encargara de la organización de la boda por poderes y de la posterior jornada hasta la frontera, un protagonismo del valido que se encargan de destacar las relaciones ${ }^{45}$.

El séquito llegó a Burgos a mediados del mes de septiembre, aunque no se especifica el día en los panfletos, donde tuvieron que esperar cerca de un mes hasta el

42 Universidad de Barcelona, biblioteca general, área de reserva, B-59/3/42-42: Los desposorios y casamientos del principe de las Españas, nuestro Señor Don Felipe, Qarto deste nombre, con la serenissima Madama Ysabel de Bourbon, hija mayor de los Reyes Christianissimos de Francia, con todas las ceremonias que en esto passaron, desde diez y siete de Otubre, hasta diez y ocho, que se celebraron dichos desposorios y casamientos, Barcelona, 1615; Biblioteca Universitaria de Sevilla, A109/085(079): Segunda relacion de los casamientos del Principe de las Españas, nuestro señor don Felipe Quarto deste nombre, con la serenissima Madama Ysabel de Bourbon, hija mayor de los Reyes Christianissimos de Francia, con todas las ceremonias, que en esto passaron, Sevilla, 1615.

${ }^{43}$ Esa ausencia de información puede responder a la necesidad, tanto española como francesa, de ocultar en las relaciones la ausencia de los Príncipes de la Sangre en la ceremonia. Dubost, "La reina de la paz".

${ }^{44}$ Chevalier, 97-100.

45 Relacion de la iornada, y casamientos, y entregas de España, y Francia, s. 1., s. a. Referencia obtenida de Simón Díaz, Relaciones de actos públicos, 94-98. 
día fijado para la celebración del enlace matrimonial. Las relaciones conservadas retoman la descripción con lo sucedido el día 17 de octubre. De forma análoga a lo acaecido en Francia, esa tarde el embajador galo fue conducido, por el conde de Altamira, caballerizo mayor, hasta el palacio que ocupaba Felipe III en la ciudad para presentar los poderes concedidos por Luis XIII para que el duque de Lerma, en su nombre, se desposara con la infanta Ana. Los datos sobre la recepción son muy escasos, apenas mencionando que presentó sus respetos a los reyes y fue enviado a ver a Lerma. Sin embargo, sí es más prolífica la descripción sobre las fiestas celebradas en la ciudad esa noche. Hubo luminarias, repique de campanas, salvas y cohetes por toda la ciudad; y los caballeros de Burgos organizaron un desfile que recorrió las inmediaciones de palacio y las principales calles de la ciudad, ataviados con vestidos propios de las modas francesa, flamenca, borgoñona, turca y española. Además, en palacio se organizó un sarao que duró hasta la madrugada.

La jornada en que se celebraría la ceremonia, el 18 de octubre, comenzó con la salida del acompañamiento del duque de Lerma, vestidos con librea como la del rey, a recoger al valido. El séquito, según los panfletos, lo formaban oficiales de caballería; veinticuatro lacayos y doce pajes; el caballerizo de la Orden de Santiago; y don Rodrigo Calderón y el conde de Olivares como gentileshombres, «aderezados con mucho oro». Cerraban la comitiva toda una serie de coches y carrozas ricamente decorados. A las once pusieron rumbo a la catedral, con el duque de Lerma ricamente vestido de terciopelo blanco y negro con bordado de perlas que hacían «que apenas se veía el terciopelo». Estas son las muestras de esplendor a las que hacíamos cuando mencionábamos que, en la descripción de la corte francesa, no se destacaban tanto como en la española.

Al mismo tiempo, los Grandes, los títulos del reino y los caballeros de la ciudad fueron a palacio a aguardar a que saliera el rey, quien lo hizo media hora después de que su valido hubiera emprendido la marcha hacia el templo. Felipe III iba vestido de negro, con capa y gorra «con muchos oros y piedras», y luciendo el Toisón de Oro. Las relaciones también detallan pormenorizadamente los ricos atavíos de los principales nobles que acompañaron al monarca.

Ante la entrada de la catedral recibió a las comitivas el cabildo de la ciudad, y en el interior esperaba el arzobispo, encargado de oficiar la ceremonia. En el templo se había levantado, en la capilla mayor, un tablado donde se ubicaría la familia real. Las relaciones detallan minuciosamente la celebración de la ceremonia, oficiada por el arzobispo, consistente en una misa cantada, «ceremonias del desposorio» y besamanos a la ya reina de Francia ${ }^{46}$. De la comitiva de vuelta a palacio apenas se detalla nada más que la infanta abandonó la catedral con la cola de su vestido sujetada por la condesa de Altamira.

A mediodía comenzaron las celebraciones con una comida en público del rey, la reina y el príncipe, y por la noche se organizó otro sarao en palacio. Esa misma

\footnotetext{
${ }^{46}$ Ese es el tratamiento que se le da en todas las relaciones a partir de la descripción de la ceremonia nupcial.
} 
noche hubo también fiestas por toda la ciudad, aunque los mayores festejos llegaron el lunes.

Ese día el duque de Lerma ofreció un banquete en honor de Ana de Austria y Luis XIII al que fueron invitados todos los caballeros de la ciudad y los aristócratas llegados a Burgos acompañando a la corte. Esa misma tarde se organizó en la ciudad, en la plaza mayor, una corrida de toros y juego de cañas, estando presentes el rey y la corte. Concluidas esas actividades, Felipe III y sus hijos hicieron un recorrido por la villa antes de regresar a palacio donde hubo un nuevo sarao ${ }^{47}$.

También se da cuenta en las relaciones de las fiestas que hubo en Madrid, una vez llegó la noticia de que ya se habían celebrado los enlaces. Durante tres noches hubo luminarias por toda la ciudad y repicaron las campanas de iglesias y monasterios para celebrar los matrimonios ${ }^{48}$.

Una vez celebradas las bodas por poderes, quedaba celebrar el encuentro entre las cortes española y francesa para el intercambio de princesas, el cual tendría lugar en el río Bidasoa, frontera natural entre ambos reinos. Ana de Austria partió de Burgos hacia el punto de reunión el 24 de octubre, efectuando una pomposa salida de la villa, acompañada del duque de Lerma, mientras que Felipe III lo hizo el día 25. Por su parte, el príncipe Felipe y los infantes se quedaron en la ciudad burgalesa a la espera de que la comitiva real regresara.

\subsection{El encuentro del Bidasoa}

Se menciona en los panfletos que, previamente a la partida de Burgos, se nombró nuevos integrantes de la cámara del príncipe. Los designados fueron el conde de Olivares, el de Paredes, el de Santisteban y el Comendador Mayor de Montesa como gentileshombres de la cámara; el conde de Saldaña como caballerizo mayor; y el duque de Uceda mayordomo mayor y sumiller de $\operatorname{corps}^{49}$. Una información, si bien relevante,

\footnotetext{
${ }^{47}$ Biblioteca Universitaria de Sevilla, A109/085(078): Relacion de los felicissimos casamientos de los Reyes y Principes de España, y Francia, quien fueron los interpretes, los prelados que los desposaron, las solennes fiestas que se hizieron, y las personas de titulos que se hallaron en ello; la victoria que tuvo el gran Mariscal de Francia contra el Principe de Conde, revelado contra su rey, y otras cosas notables, y de mucho gusto, Sevilla, 1615; Universidad de Barcelona, biblioteca general, área de reserva, B-59/3/42-41: Los grandiosos desposorios de la sereenissima Infanta de España con el Christianissimo Luys Rey de Francia 13 y la sumptuosa jornada que el Duque de Lerma ha hechos a la raya de Francia acompañando a la señora Infanta hasta la entrega y las grandes fiestas que se han hecho el dia que salieron desta Ciudad de Burgos sus Magestades, Barcelona, 1615; Biblioteca Universitaria de Sevilla, A110/127(34): Tercera relacion de los felicissimos casamientos del Principe Don Filipe nuestro señor con la serenissima Madama Ysabela de Borbon, y del Christianissimo Ludovico Rey de Francia con la Reyna doña Ana Maria de Austria. $Y$ de la renunciacion que bizo de sus derechos a España en el Rey su padre, señor nuestro. La salida de Burgos a su viage, hasta donde va su Magestad con su bija, y espera de la serenissima Princesa de España, Sevilla, 1615.

48 Biblioteca Universitaria de Sevilla, A109/085(078): Relacion de los felicissimos casamientos de los Reyes y Principes de España, y Francia, quien fueron los interpretes, los prelados que los desposaron, las solennes fiestas que se hizieron, y las personas de titulos que se hallaron en ello; la victoria que two el gran Mariscal de Francia contra el Principe de Conde, revelado contra su rey, y otras cosas notables, y de mucho gusto, Sevilla, 1615.

${ }^{49}$ Biblioteca Universitaria de Sevilla, A109/085(078): Relacion de los felicissimos casamientos de los Reyes y Principes de España, y Francia, quien fueron los interpretes, los prelados que los desposaron, las solennes fiestas que se bizieron, y las personas de titulos que se hallaron en ello; la victoria que tuvo el gran Mariscal de Francia contra el Principe
} 
poco relacionada con los matrimonios en sí, por lo que suponen otra muestra más de esa otra finalidad de las relaciones de sucesos, además de la informativa, de mostrar quiénes ostentaban el poder o estaban cercanos a él. En este caso, aristócratas cercanos a la figura del duque de Lerma.

Sobre el recorrido tanto de Ana de Austria como de su padre se realiza una minuciosa descripción en varias relaciones, especificando todas las etapas del viaje, aunque no las detallaremos aquí por no hacer excesivamente densa la narración. Felipe III únicamente fue hasta Vitoria, donde llegó el día 29 de octubre, ciudad en la que se despidió de su hija y aguardaría el regreso del duque de Lerma con Isabel de Borbón. Parece que el motivo de que ni el monarca español ni María de Médicis acudieran al encuentro del Bidasoa fue, de nuevo, la búsqueda de igualdad. Y es que, en caso de encuentro personal, la regente estaría en inferioridad con respecto al Austria, y se prefirió evitar una situación que rompiera la equidad presente en todo el proceso de los matrimonios ${ }^{50}$.

De la villa alavesa partieron el día 30 el valido y la nueva reina de Francia, afrontando aún otra semana de recorrido antes de llegar a Fuenterrabía, el día 7 de noviembre, dos jornadas antes de la fecha acordada para el encuentro con la comitiva francesa ${ }^{51}$. Si bien no se conservan relaciones que lo mencionen, es de esperar que en todas las ciudades en las que hicieron escala en su camino hasta la frontera la comitiva real realizara entradas solemnes, visitara las villas, engalanadas para la ocasión, y se celebraran fiestas en su honor ${ }^{52}$.

La ceremonia de intercambio, como no podía ser de otra manera, había sido minuciosamente preparada durante los meses previos a esa fecha. El aparato ideado para llevar a las princesas a sus nuevas cortes fue una idea francesa, aceptada por el Consejo de Estado español. Consistía en lo siguiente:

El mejor medio que se podía tomar para lo de las Entregas, que fuese en tres barcas, la una hecha de dos barcos, y que uno sea de España, y el otro de Francia, y que juntos estos dos sobre ellos se hiciese un aposento lucido que tuviese una grande entrada a la parte de España, y otra a la de Francia, y este barco estuviese en medio del río. Que

de Conde, revelado contra su rey, y otras cosas notables, y de mucho gusto, Sevilla, 1615; Universidad de Barcelona, biblioteca general, área de reserva, B-59/3/42-41: Los grandiosos desposorios de la sereenissima Infanta de España con el Christianissimo Luys Rey de Francia 13 y la sumptuosa jornada que el Duque de Lerma ha hechos a la raya de Francia acompañando a la señora Infanta hasta la entrega y las grandes fiestas que se han hecho el dia que salieron desta Ciudad de Burgos sus Magestades, Barcelona, 1615.

${ }^{50}$ Río Barredo, "Imágenes para una ceremonia de frontera", 159-161.

${ }^{51} \mathrm{BNE}, \mathrm{VC} / 226 / 54$ : Relacion del efecto de la iornada del Rey don Filipe nuestro señor, y del entrego de la Christianissima Reyna de Francia doña Ana Mauricia de Austria su hija, y del recibo de la serenissima Princesa Madama Ysabela de Borbon; las ceremonias que en este acto uvo de la una, y otra parte, y su conclusion. Todo lo qual fue en Irun, Lunes nueve de Noviembre deste presente año. Y de la partida a Francia, y buelta del Rey nuestro señor con su nueva hija, Sevilla, 1615; Barcelona, 1615. Universidad de Barcelona, biblioteca general, área de reserva, B-59/3/42-41: Los grandiosos desposorios de la sereenissima Infanta de España con el Christianissimo Luys Rey de Francia 13 y la sumptuosa jornada que el Duque de Lerma ha hechos a la raya de Francia acompañando a la señora Infanta hasta la entrega y las grandes fiestas que se han hecho el dia que salieron desta Ciudad de Burgos sus Magestades.

52 Ezequiel Borgognoni, "Viaje de princesas y cambio identitario en la España de los Austrias", Memoria y Civilización 22 (2019): 615. 
fuera de este barco haya otros dos, el uno de la parte de España y el otro de la de Francia, y a un mismo tiempo entren la Reina Infanta y Princesa cada una en su barco, y lleguen a la barca grande entrando cada una por su parte, y que quien entrare a la Reina Infanta, reciba a la Princesa y se vuelva con S. A. a España, y quien hubiere traído a la Princesa, reciba a la Reina Infanta y se vuelva a Francia ${ }^{53}$.

Se acordó, además, el acompañamiento que podrían llevar las infantas en las barcas; que sus soldados de guardia no llevarían arcabuces; y que los soldados de infantería que hubieran escoltado a las delegaciones tanto española como francesa debían quedarse en Irún y Hendaya, respectivamente. Estas medidas de protección obedecen al recelo existente entre ambas cortes, acentuado, según el profesor García, por las históricas pretensiones que Francia había albergado sobre el río Bidasoa que habían creado ciertos recelos en la Monarquía Hispánica ${ }^{54}$.

Tan solo una de las relaciones de sucesos conservada narra cómo fue el intercambio, la mayoría de los panfletos publicados ese año se centraban en lo acaecido en Burgos. Según esa descripción, el día 9 de noviembre ocurrió lo siguiente:

Ambas comitivas salieron al tiempo hacia el lugar del encuentro. En medio del rio habia un corredor armado sobre cuatro barcas, dos de la parte de españa y dos de la de francia y a cada lado habia una gabarra. Todo estaba cubierto y las casas de cada lado del rio decoradas con ricas tapicerias, entraron a las casas al tiempo y embarcaron al tiempo. En las gabarras habia seis soldedados de las guaradas de cada uno. A ana la metio en la barca el duque de uceda y entraron en la barca todos los grandes titulos que habian ido y el presidente de hacienda. A isabel la metio el duque de guisa. Las gabarras llegaron al tiempo a la plataforma donde estaban los secretarios de estado antonio de aroztigui y monsieur de pisius. Con ana iban sus damas y la duquesa de riosco y con isabel la duquesa de niberes, hermana de guisa. Alli se pidieron las dos cuñadas las manos la una a la otra. Estuvieron muy poco tiempo, pasando las princesas a las barcas, uceda y guisa pidieron a los secretarios los testimonios y se fueron a sus casas $^{55}$.

Concluido el intercambio, la comitiva española regresó a Vitoria, donde los recibió Felipe III, de allí pasaron a Burgos a encontrarse con el príncipe y los infantes y emprendieron el regreso, primero visitando Valladolid y, después, poniendo rumbo hacia la capital ${ }^{56}$. Cuando se estaban acercando a Madrid, en lugar de entrar

53 AGS, Estado, K-1626, no 65: Consulta del Consejo de Estado del 25 de agosto de 1615.

${ }^{54}$ Bernardo José García García, "Dobles bodas reales. Diplomacia y ritual de corte en la frontera (1615-1729)", en Sevilla y corte. Las artes y el Lustro Real (1729-1733), comp. Nicolás Morales y Fernando Quiles García (Madrid: Casa de Velázquez, 2010), 25-26

55 BNE, VC/226/54: Relacion del efecto de la iornada del Rey don Filipe nuestro señor, y del entrego de la Christianissima Reyna de Francia doña Ana Mauricia de Austria su bija, y del recibo de la serenissima Princesa Madama Ysabela de Borbon; las ceremonias que en este acto uvo de la una, y otra parte, y su conclusion. Todo lo qual fue en Irun, Lunes nueve de Noviembre deste presente año. Y de la partida a Francia, y buelta del Rey nuestro señor con su nueva bija, Sevilla, 1615.

${ }^{56}$ Biblioteca Universitaria de Sevilla, A110/127(34): Tercera relacion de los felicissimos casamientos del Principe Don Filipe nuestro señor con la serenissima Madama Ysabela de Borbon, y del Christianissimo Ludovico Rey 
directamente decidieron enseñar a la princesa algunos de los Reales Sitios. Fueron primero a El Escorial, «la Octava Maravilla», y después al palacio de El Pardo, donde se celebraron algunas cacerías en honor de Isabel de Borbón.

Finalmente, llegaron a Madrid el 18 de diciembre, haciendo noche en el monasterio de San Gerónimo. A la mañana siguiente, en el propio monasterio, los consejos hicieron un besamanos a la princesa y las autoridades y representantes de la villa acudieron para darle la bienvenida. Una vez concluidos esos encuentros, la comitiva puso rumbo a palacio a través de calles ricamente engalanadas con telas, terciopelos y damascos; así como distintas muestras de arquitectura efímera, de las que las relaciones destacan un arco triunfal erigido junto al palacio de Lerma. Isabel hizo el recorrido en una yegua blanca y cubierta por un palio ofrecido por la villa de Madrid; abrían la comitiva los más insignes títulos del reino, incluyendo el duque de Lerma, el más cercano a la princesa. Se detuvieron en la iglesia de Santa María a rezar antes de concluir el recorrido hasta palacio ${ }^{57}$.

Por su parte, Luis XIII tuvo mayores problemas para presentar a Francia a su nueva reina. La comitiva que había acudido a la frontera regresó a Burdeos, donde se había quedado María de Médicis. Allí hubo que repetirse la ceremonia matrimonial, esta vez con Ana presente, el 25 de noviembre. No obstante, mientras que Isabel de Borbón hacía su entrada solemne en Madrid a mediados de diciembre, Luis y Ana tuvieron que esperar para hacer lo propio en París hasta el 16 de mayo de 1616 dados los conflictos internos del reino galo ${ }^{58}$.

En las relaciones españolas apenas sí hay menciones a la inestabilidad interna francesa, unos problemas que comenzaron tiempo antes del intercambio de princesas, como ya hemos explicado previamente. Continuaba así el intento, constante en todas las relaciones de sucesos, de transmitir una imagen de tranquilidad y de unidad. No obstante, sí hay un panfleto español que hace alusión a esos disturbios en Francia, si bien todo lo que refleja es que el Príncipe de Condé «anda alborotando, y el Mariscal de Francia le ha desbaratado y puesto en huida en un bravo encuentro», y que no había logrado apoyos ni de Inglaterra ni de Países Bajos y se había tenido que refugiar en La Rochelle $^{59}$. La descripción transmite la idea de una situación mucho más controlada por el gobierno galo de lo que en realidad estaba, como muestra que no pudieran regresar a la capital hasta la primavera de 1616. En este aspecto las relaciones de ambos estados, en vez de competir en superioridad, coinciden en menorar ese asunto interno asumiendo el común interés en concluir las bodas.

\footnotetext{
de Francia con la Reyna doña Ana Maria de Austria. Y de la renunciacion que hizo de sus derechos a España en el Rey su padre, señor nuestro. La salida de Burgos a su viage, hasta donde va su Magestad con su bija, y espera de la serenissima Princesa de España, Sevilla, 1615.

${ }^{57}$ Relacion de la iornada, y casamientos, y entregas de España, y Francia, s. 1., s. a. Referencia obtenida de Simón Díaz, Relaciones de actos públicos, 94-98.

${ }^{58}$ Chevallier, Luis XIII, 100; Perceval, Opinión pública y publicidad, 65-67.

${ }^{59}$ Biblioteca Universitaria de Sevilla, A109/085(078): Relacion de los felicissimos casamientos de los Reyes y Principes de España, y Francia, quien fueron los interpretes, los prelados que los desposaron, las solennes fiestas que se bizieron, y las personas de titulos que se hallaron en ello; la victoria que tuvo el gran Mariscal de Francia contra el Principe de Conde, revelado contra su rey, y otras cosas notables, y de mucho gusto, Sevilla, 1615.
} 
Por su parte, las relaciones de sucesos que narran lo sucedido en España en 1615, mucho más centradas en la boda que en el intercambio, se afanaron en transmitir la idea de opulencia y magnificencia en todo el reino. Son constantes las descripciones de los ricos atuendos de la casa real y la aristocracia, así como de la magnificencia de las fiestas ofrecidas. Unas celebraciones para las que, igual que pasaba en los panfletos de 1612, no hay ninguna mención a Francia ni a que la unión con el reino galo sea motivo de alegría, tan solo se festeja el matrimonio de una infanta española, transmitiendo la idea de que la Monarquía Hispánica es muy superior al estado vecino y que una unión con él no supone un motivo de gran algarabía, como si sucede al revés. Un último aspecto que merece la pena destacar de estas relaciones es relativo a la renuncia de Ana de Austria a los derechos sucesorios de las Coronas de Castilla y Aragón. Ya mencionábamos páginas atrás que esto fue uno de los puntos principales de negociación en 1612, sin embargo, ninguna de las relaciones de sucesos publicadas ese año hace alusión a dicha renuncia y tan solo una de 1615 lo hace. En ésta, además de fijar erróneamente la fecha en 1615, presenta el acto como una acción voluntaria de la infanta que quiso hacer una donación a su padre antes de marcharse a Francia ${ }^{60}$.

\section{CONCLUSIONES}

Un gran evento como fueron las dobles bodas de 1615 fue aprovechado por la monarquía, como sucedió, también, en Francia, para elaborar una intensa campaña de propaganda que legitimara la decisión de unir dos dinastías tradicionalmente enfrentadas. Son muchas las ideas que se tratan de transmitir a través de las relaciones de sucesos que hemos analizado en las páginas anteriores.

En primer lugar, se presentan dos reinos cuyos panoramas políticos internos son de absoluta cohesión en torno al poder. Son constantes las menciones a la presencia de prácticamente la totalidad de la aristocracia en torno al monarca en todos los actos, así como a su participación en los distintos eventos relatados en los panfletos, tanto en la Monarquía Hispánica como en Francia. Especialmente notable es en este último caso, como ya hemos reseñado a lo largo del artículo, pues su situación interna era completamente opuesta a la tranquilidad que se desprende de las descripciones, protagonizada por revueltas nobiliarias. Pero era ésta una realidad que no convenía reflejar, no solo por la inconveniencia de aliarse con un gobierno inestable, sino porque precisamente el acercamiento a la Monarquía Hispánica era uno de los principales motivos de protesta de los aristócratas levantiscos.

Las relaciones de sucesos también muestran con claridad quién ostentaba el poder en la corte de Felipe III. El duque de Lerma aparece como figura omnipresente en todos los panfletos, tanto los de 1612 como los de 1615 , siempre jugando un papel

\footnotetext{
${ }^{60}$ Biblioteca Universitaria de Sevilla, A110/127(34): Tercera relacion de los felicissimos casamientos del Principe Don Filipe nuestro señor con la serenissima Madama Ysabela de Borbon, y del Christianissimo Ludovico Rey de Francia con la Reyna doña Ana Maria de Austria. Y de la renunciacion que hizo de sus derechos a España en el Rey su padre, señor nuestro. La salida de Burgos a su viage, hasta donde va su Magestad con su bija, y espera de la serenissima Princesa de España, Sevilla, 1615.
} 
fundamental: acoger en su residencia al duque de Humena, encargarse de los preparativos de la boda e intercambio, representar a Luis XIII en el enlace o ser el anfitrión de la, según las relaciones, principal celebración del matrimonio. Pero la muestra del poder del valido no se limita al protagonismo que le conceden, probablemente no muy alejado del que tuvo en realidad, sino que se plasma también en cómo se destacaron a aquellas personas cercanas a él. En las constantes menciones a la aristocracia que participó en los distintos actos apenas se especificaba qué títulos eran, haciendo alusiones genéricas a la nobleza. Sin embargo, algunas excepciones que encontramos son las citas al duque de Uceda, su propio hijo; al conde y a la condesa de Altamira, siendo ella la hermana de Lerma; o al conde de Olivares y don Rodrigo Calderón. Todos ellos personas del círculo más cercano al valido y que gozan, además, de gran protagonismo en las descripciones.

Pero, posiblemente, la principal idea que se quiso transmitir es que la Monarquía Hispánica era una gran potencia, apreciable en distintos aspectos. Políticamente, se mostraba un estado que continuaba siendo la principal potencia de Europa, a pesar de sus dificultades financieras, aquélla con la que todos querían unirse y que podía llevar la prosperidad a los reinos aliados; así como ser un adalid del cristianismo, el candidato ideal para acabar con las herejías. Al mismo tiempo, se muestra una Francia, principal rival político y candidata a ser la potencia dominante en el continente, como un estado claramente inferior a la Monarquía y necesitado, según las versiones españolas, de un acercamiento a ésta.

Además, se muestra a los reinos españoles en una situación boyante y que atraviesa un momento de gran esplendor. Esto se puede apreciar en las riquezas de que hacen gala tanto la aristocracia y miembros de la corte, así como por supuesto el monarca y la familia real, como muestran las minuciosas descripciones de los ricos ropajes y adornos de los nobles. Pero también en el ambiente festejante de la sociedad, los engalanamientos de las ciudades y las celebraciones que ofrecieron. Lo cual, además, refuerza la idea de cohesión social que hemos mencionado a lo largo del artículo.

Estos mensajes eran especialmente relevantes habida cuenta del contexto político español del momento, con el desarrollo de la Pax Hispanica. Ante esa política desarrollada por Felipe III, como ya hemos mencionado, hubo voces de reputacionistas que consideraban que era una pérdida de prestigio. Por eso revestía gran importancia transmitir una imagen de esplendor de los reinos y de contento social. Así, aprovechando un evento que atraería tanto la atención como fueron los matrimonios se presenta una Monarquía Hispánica como una gran potencia, muy superior a sus rivales, en un momento de brillantez. 


\section{REFERENCIAS BIBLIOGRÁFICAS}

Allen, Paul, Felipe III y la Pax Hispanica (1598-1621) (Madrid: Alianza Editorial, 2001).

Arias Saavedra, Inmaculada, "Ecos de las alianzas dinásticas entre Francia y España en la imprenta andaluza durante los siglos XVI, XVII y XVIII", Tiempos modernos 36 (2018): 302-330.

Bouza Álvarez, Fernando, "La propaganda en la Edad Moderna Española: Medios, agentes y consecuencias de la comunicación política", en Campo y campesinos en la España moderna. Culturas políticas en el mundo hispano, ed. María José Pérez Álvarez y Alfredo Martín García (León: Fundación Española de Historia Moderna, 2012), 281-300.

Borgognoni, Ezequiel, "Viaje de princesas y cambio identitario en la España de los Austrias", Memoria y Civilización 22 (2019): 611-633. DOI https://doi.org/10. 15581/001.22.030.

Chartier, Roger, ed., Les Usages de l'imprimé (París: Fayard, 1986).

Chevallier, Pierre, Louis XIII (París: Fayard, 1979).

Dubost, Jean-François, "La reina de la paz. Conservación, concordia y arte de la diplomacia bajo la regencia de María de Médicis (1610-1614)", en El arte de la prudencia. La Tregua de los Doce Años en la Europa de los Pacificadores, ed. Bernardo José García García, Manuel Herrero Sánchez y Alain Hugon (Madrid: Fundación Carlos de Amberes, 2012).

Duccini, Héléne, Faire voir, faire croir. L’opinion publique sous Louis XIII (París: Champ Vallon, 2003).

Eiras Roel, Antonio, "La política francesa de Felipe III: las tensiones con Enrique IV”, Hispania 118 (1971): 245-336.

Enciso Recio, Luis Miguel, "Los mensajes de la propaganda en la España de Felipe III y Felipe IV. La palabra hablada y la palabra escrita", en Estudios de Historia Moderna en homenaje a la profesora Emilia Salvador Esteban, vol. II, ed. Ricardo Franch Benavent y Rafael Benítez Sánchez-Blanco (Valencia: Publicacions Universitat de Valéncia, 2008), 971-1002.

Feros, Antonio, El duque de Lerma. Realeza y privanza en la España de Felipe III (Madrid: Marcial Pons, 2002). 
García García, Bernardo José, La Pax Hispanica. Política exterior del duque de Lerma, (Lovaina: Leuven University Press, 1996).

—, "Dobles bodas reales. Diplomacia y ritual de corte en la frontera (1615-1729)", en Sevilla y corte. Las artes y el Lustro Real (1729-1733), comp. Nicolás Morales y Fernando Quiles García (Madrid: Casa de Velázquez, 2010), 24-40.

Hayden, J. Michael, "Continuity in the France of Henri IV and Louis XIII: French foreign policy (1589-1615)", Journal of Modern History XLV (1973). DOI https://doi.org/10.1086/240888.

-, "Political pamphlets and historians of Early Modern France. The example of 16141615”, Canadian Journal of History 21 (1986): 143-165. DOI https://doi.org/10 $.3138 /$ cjh.21.2.143.

Hugon, Hugon, Au service du Roi Catholique: Honorables ambassadeurs et divins espions face à la France (Madrid: Casa de Velázquez, 2004).

—, "La monarquía francesa en la borrasca de las paces. De Vervins a los matrimonios con los Habsburgo (1598-1615)", en Tiempo de Paces. La Pax Hispanica y la Tregua de los Doce Años, dir. Bernardo José García García (Madrid: Fundación Carlos de Amberes, 2009), 127-142.

Labourdette, Jean-François, Poussou, Jean-Pierre y Vignal, Marie-Catherine, eds., Le Traité e Vervins (Paris: Presses de l’Université de Paris-Sorbonne, 2000).

Maldonado Cuns, Ana María“La relación verdadera de López Maldonado y su paralelismo con otras relaciones de la época para explicar la boda de Ana de Austria y Luis de Borbón", en Las relaciones de sucesos en los cambios políticos y sociales de la Europa Moderna, coord. Jorge García López y Sonia Boadas Cabarrocas (Barcelona: UAB Servei de Publicacions, 2015), 83-102.

Maravall, José Antonio, La Cultura del Barroco. Análisis de una estructura histórica (Barcelona: Ariel, 1975).

Perceval, José María, “Opinión pública y publicidad (siglo XVII). Nacimiento de los espacios de comunicación pública en torno a las bodas reales de 1615 entre Borbones y Habsburgo" (Tesis Doctoral, Universidad Autónoma de Barcelona, 2004).

Pierre, B., "El partido devoto y la paz en Francia en la década de 1610", en El arte de la prudencia. La Tregua de los Doce Años en la Europa de los Pacificadores, ed. Bernardo José García García, Manuel Herrero Sánchez y Alain Hugon (Madrid: Fundación Carlos de Amberes, 2012), 345-364. 
Río Barredo, María Jesús del, "Imágenes para una ceremonia de frontera. El intercambio de las princesas entre las cortes de Francia y España en 1615", en La historia imaginada. Construcciones visuales delpasado en la Edad Moderna, dir. Diana Carrió-Invernizzi y Joan Lluís Palos (Madrid: Centro de Estudios Europa Hispánica, 2008), 153-182.

—, "Infancia y educación de Ana de Austria en la Corte española (1601-1615), en Ana de Austria. Infanta de España y reina de Francia, dir. Chantal Grell (Madrid: Centro de Estudios Europa Hispánica, 2009), 11-40.

Ruiz Ibáñez, José Javier, "Cette disgracê de guerre. La opción española en la política francesa de 1598 a 1641”, en SANZ CAMAÑES, P. (coord.), La Monarquía Hispánica en tiempos de El Quijote, coord. Porfirio Sanz Camañes (Madrid: Sílex, 2005), 529-556.

Simón Díaz, José, ed., Relaciones de actos públicos celebrados en Madrid, (1541-1650), (Madrid: Instituto de Estudios Madrileños, 1982).

Vidal, Claudine, y Pilleboue, Frédérique, eds., La paix de Vervins: 1598 (Laon: Fédération des sociétés d'histoire et d'archéologie de l'Aisne,1998).

Recibido: 4 de junio de 2020 Aprobado: 9 de agosto de 2020 